\title{
Rare Case of Acute Aortic Dissection in a Young Non-Hypertensive and Non-Pregnant Lady
}

Manish Barman*, Bendaas Djamel and Joji Mathews

Department of Cardiology, Heart Care Center, Al Ahli Hospital, Doha, Qatar

\begin{abstract}
Acute aortic dissection is a catastrophic episode that usually presents as a sudden, painful, ripping sensation in the chest or back. It has an estimated annual incidence of approximately 5 to 30 per million. The primary event in aortic dissection is a tear in the aortic intima. The most important predisposing factor for acute aortic dissection is systemic hypertension. Other predisposing factors include disorders of collagen (Marfan syndrome, Ehlers-Danlos syndrome, bicuspid aortic valve, aortic coarctation, Turner syndrome, coronary artery bypass graft surgery, previous aortic valve replacement, crack cocaine use, strenuous resistance training and trauma.

Approximately half of the aortic dissection observed in women under 45 years old has been reported to be related to pregnancy. Herein, we present a case of type A aortic dissection diagnosed in a 37 year old non hypertensive, nonpregnant female. Aortic dissection is not uncommon or impossible in a young healthy and previously asymptomatic female. A high level of suspicion is required for prompt diagnosis and treatment.
\end{abstract}

Keywords: Acute aortic dissection; Non-pregnant female

\section{Introduction}

Aortic dissection is generally suspected based on a patient's history and physical examination. Patients with an aortic dissection typically present with severe, sharp or 'tearing' back pain (in dissection distal to the left subclavian artery) or anterior chest pain (in ascending aortic dissection). Painless dissection has been reported but is relatively rare [1-5]. In an analysis of 977 patients from the International Registry of Acute Aortic Dissection, only 63 patients (6.4\%) had no pain [5]. Patients with painless dissection were slightly older (mean age 67 years versus 62 years) and had a type A dissection more often (75\% versus $61 \%$ ). A history of diabetes, aortic aneurysm or cardiovascular surgery was more common in patients with painless dissection. Presenting symptoms of syncope, heart failure or stroke were seen more often in this group. In-hospital mortality was significantly higher than for patients presenting with pain (33\% versus $23 \%$ ) [6,7].

All mechanisms that weaken the aortic wall, the aortic lamina media in particular, lead to higher wall stress, which can induce aortic dilatation and aneurysm formation, eventually resulting in aortic dissection or rupture.

\section{Differential diagnosis should include}

- Myocardial ischemia

- $\quad$ Pericarditis

- Pulmonary embolus

- Aortic regurgitation without dissection

- Aortic aneurysm without dissection

- Musculoskeletal pain

- $\quad$ Mediastinal tumors

- $\quad$ Pleuritis

- $\quad$ Cholecystitis

- Atherosclerotic or cholesterol embolism
- $\quad$ Peptic ulcer disease or perforating ulcer

- $\quad$ Acute pancreatitis

Routine blood tests are generally non-diagnostic and imaging studies are not performed until the patient is stabilized medically. In general terms, a bedside transthoracic echo is an invaluable tool.

Acute dissections involving the ascending aorta are considered surgical emergencies. In contrast, dissections confined to the descending aorta are treated medically unless the patient demonstrates progression or continued hemorrhage into the pleural or retroperitoneal space. Patients with suspected aortic dissection should be admitted to an intensive care unit as rapidly as possible for confirmation of the diagnosis, pain control and reduction of systolic blood pressure to between $100 \mathrm{mmHg}$ and $120 \mathrm{mmHg}$. Patients who are hemodynamically unstable should be intubated. All patients should receive lifelong therapy with an oral beta-blocker to reduce systemic blood pressure and the rate of rise in systolic pressure, both of which will minimize aortic wall stress. Avoidance of strenuous physical activity is also recommended as another method to minimize aortic shear stress. A baseline thoracic magnetic resonance scan before discharge, with serial follow-up examinations at three, six and 12 months, even if the patient remains asymptomatic is recommended [8-22].

\section{Case Presentation}

A 37 years old lady, BMI 26, was admitted with complaints of acute onset, non-exertional, severe and stabbing lower chest and epigastric pain since one hour.The pain increased with movements and

*Corresponding author: Manish Barman, Department of Cardiology, Hear Care Center, Al Ahli Hospital, Doha, Qatar, Tel: 974-66936385; E-mail: drbarman@yahoo.com

Received February 26, 2014; Accepted April 09, 2014; Published April 16, 2014

Citation: Barman M, Djamel B, Mathews J (2014) Rare Case of Acute Aortic Dissection in a Young Non-Hypertensive and Non-Pregnant Lady. J Cardiovasc Dis Diagn 2: 154. doi:10.4172/2329-9517.1000154

Copyright: (c) 2014 Barman M, et al. This is an open-access article distributed under the terms of the Creative Commons Attribution License, which permits unrestricted use, distribution, and reproduction in any medium, provided the original author and source are credited. 
Citation: Barman M, Djamel B, Mathews J (2014) Rare Case of Acute Aortic Dissection in a Young Non-Hypertensive and Non-Pregnant Lady. J Cardiovasc Dis Diagn 2: 154. doi:10.4172/2329-9517.1000154

deep inspiration. This was associated with nausea and one episode of vomiting. She also experienced an episode of syncope with the onset of pain. She gave no history of hypertension, diabetes or bronchial asthma. Mother of two children, last child birth 5 years ago. She has no known allergies. Non-smoker and no family history of congenital heart defects.

On presentation she was a febrile with a temperature of $36.7^{\circ} \mathrm{C}$, blood pressure reading of $110 / 60 \mathrm{mmHg}$, a pulse rate of 50 beats $/ \mathrm{min}$ and a respiratory rate of 18 breaths $/ \mathrm{min}$. She was alert and oriented. On physical examination, her pupils were round, equal, and reactive to light and accommodation. There was no jugular venous distension or hepatojugular reflux. There were no carotid bruits. The chest wall was symmetric and there was no deviation of the trachea. There was good air entry bilaterally with clear breath sounds. The point of maximal impulse was located in the left fifth intercostal space anterior axillary line. Her heart sounds had a regular rate and rhythm, with a grade II/ VI mid-systolic murmur located in aortic area. There were no audible gallops or clicks. The heart sounds were not muffled and there was no pulsus paradoxus. The second heart sound was physiologically split. The abdomen was obese with no visible pulsations. The bowel sounds were normoactive. She had no palpable masses. Her abdomen was soft and nontender. Her extremities were warm to the touch, with no pallor, finger clubbing or cyanosis. Pulses were symmetrical, no radio femoral delay and there was no peripheral edema. There was no femoral bruit. No focal neurological signs. Investigations done at presentation were as follows

CBC- Mild leukocytosis, TLC 12,200/cmm, Neutrophils 74\%, lymphocytes $20 \%$, monocytes $4 \%$, eosinophil $2 \%$, Hemoglobin 13.2 $\mathrm{gm} / \mathrm{dl}$ and platelets $2.2 \mathrm{lacs} / \mathrm{cmm}$. Random blood sugar- $102 \mathrm{mg} / \mathrm{dl}$, Normal liver and kidney function tests. CRP mildly elevated $11 \mathrm{mg} /$ dl. S amylase $55 \mathrm{u} / \mathrm{L}$, Lipid profile- Total cholesterol $180 \mathrm{mg} / \mathrm{dl}$, LDL $108 \mathrm{mg} / \mathrm{dl}$, HDL $55 \mathrm{mg} / \mathrm{dl}$. Triglycerides 132.Chest X-ray- Normal lung fields and cardiac shadow. No evidence of Mediastinal widening.

On evaluation by the cardiologist, a detailed history directed at symptoms and risk factors for aortic dissection was taken but was non-contributory. An electrocardiogram and echocardiogram were ordered as preliminary tests along with $\mathrm{D}$ dimer and cardiac markers. The electrocardiogram showed a normal sinus rhythm with a rate of 50 beats $/ \mathrm{min}$. The echocardiogram showed a dilated aortic root [5.3 $\mathrm{cm}$ ] with intimal flap in the ascending aorta. D dimer was elevated 1.68 $\mathrm{mg} / \mathrm{l}[$ normal $<0.50 \mathrm{mg} / \mathrm{l}]$. Cardiac markers were within normal range (Figures 1-3).

With regard to risk factors, she had no previous cardiac catheterization, intra-aortic balloon pump or any cardiac surgery such as valve replacement.

Diagnosis of Acute aortic dissection was made and she was immediately referred to cardiovascular surgeon foremergency surgery and underwent Bentall operation with valve replacement and aortic root replacement conduit. She required IABP and inotropic support post operatively but was successfully weaned off and recovered completely. Discharge medications included Tablet bisoprolol 1.25 $\mathrm{mg} /$ daily, Crestor $10 \mathrm{mg} /$ daily and IE prophylaxis. She was advised regular follow up and her current status at 6 months is satisfactory with no evidence of further aortic root dilatation.

\section{Discussion}

The prevalence and incidence of thoracic aortic disease is increasing, as are the number of operations for thoracic aortic disease

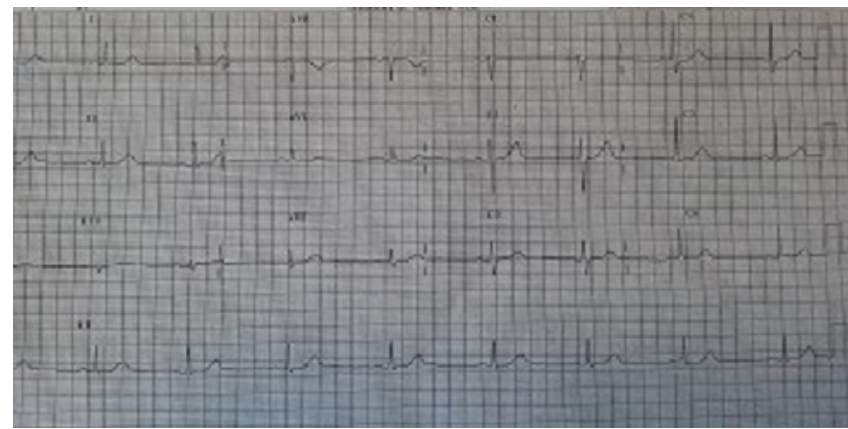

Figure 1: ECG.

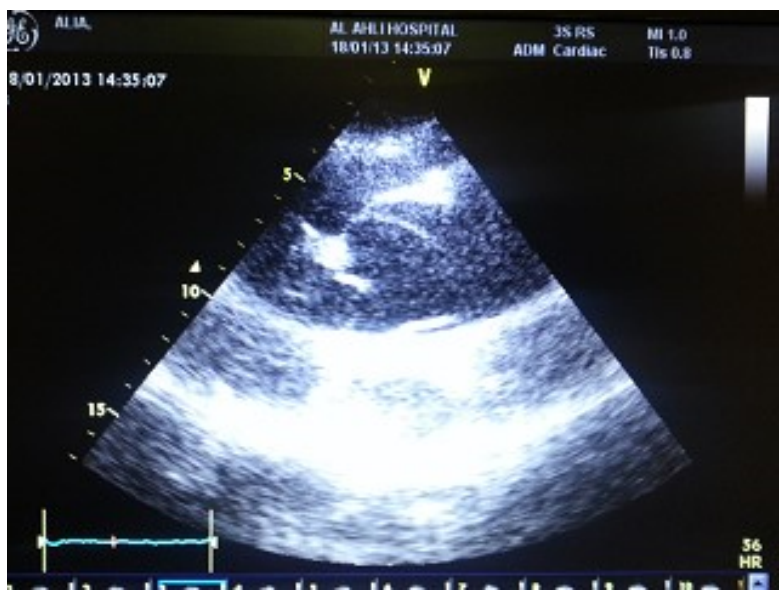

Figure 2: $\mathrm{ECHO}$

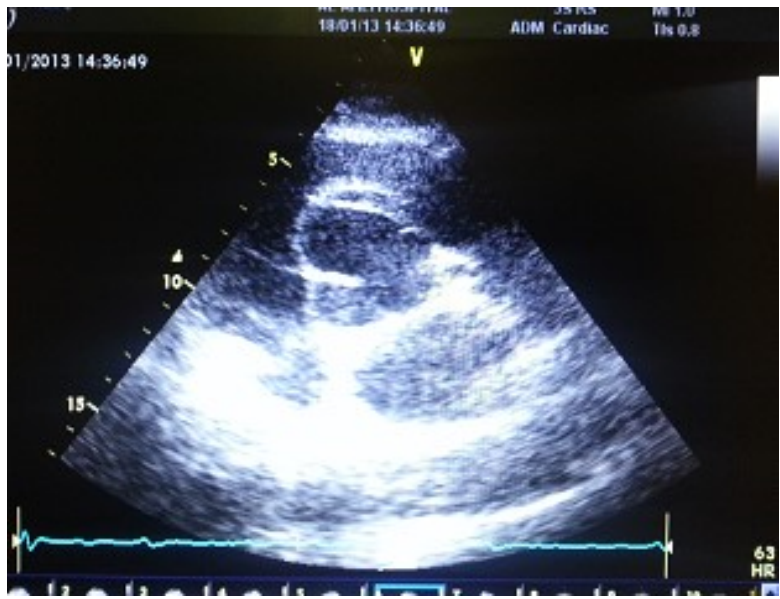

Figure 3: $\mathrm{ECHO}$

$[1,2,16]$. In one study the overall incidence rate of 10.4 per 100,000 person-years between 1980 and 1994 was more than threefold higher than the rate from 1951 to 1980 [1]. Once ruptured, emergent repair is extremely challenging with an associated mortality in the mid $90 \%$ range $[1,4]$. Overall survival for TAA has improved significantly in the past 15 years [2].

The natural history of thoracic aneurysms is progressive expansion, 
subsequent increased aneurysm wall stress and eventual rupture $[1,3]$. Aortic aneurysms can be further classified according to their morphology into fusiform or saccular categories. Aneurysms can affect different locations of the aorta: the aortic root, ascending aorta, aortic arch or the descending aorta.

There are two widely known classifications of dissections, Stanford and De Bakey. Stanford type A includes dissections that involve the ascending thoracic aorta, whereas type B dissections do not involve the ascending thoracic aorta. De Bakey type 1 dissections involve the whole aorta, type 2 dissections involve the ascending aorta and type 3 dissection involves the descending aorta. Thus, Stanford type A dissection includes De Bakey types 1 and 2, and Stanford type B equals De Bakey type 3 (Figure 4).

Many conditions can cause aneurysmal formation. The etiology may differ depending on the location of the aneurysm. The most common cause of descending aortic aneurysm is atherosclerosis, whereas the etiology for aortic root aneurysm may be associated with connective tissue disorders such as Marfan syndrome, Ehlers-Danlos syndrome and bicuspid aortic valve disease. Other etiologies include infection, inflammation, trauma, dissection and idiopathic.

Most patients are asymptomatic, and the aneurysm is discovered incidentally by chest radiography, echocardiography or CT. Aortic aneurysms may manifest with symptoms late in the course of the disease. Progressive dilation of the ascending aneurysm may cause dilation of the aortic annulus, with resultant aortic regurgitation. This represents a significant volume overload on the left ventricle, resulting in progressive left ventricular dilation and failure. Compression of the adjacent structure may lead to chronic chest pain.

Acute sudden onset of severe pain is the typical manifestation of aortic dissection, but a wide variety of symptoms can be present. The patient may have symptoms suggestive of congestive heart failure, stroke, shock or loss of distal pulse.

Presenting symptoms in acute type A aortic dissection among the patients with aortic diameters of less than $5.5 \mathrm{~cm}$ were back pain, radiating pain, abrupt onset of pain and neurological deficits. On presentation, $32 \%$ of patients had hypertension, $12.8 \%$ were in shock and $26 \%$ had clinical signs of pulse deficits [10]. Among the signs of

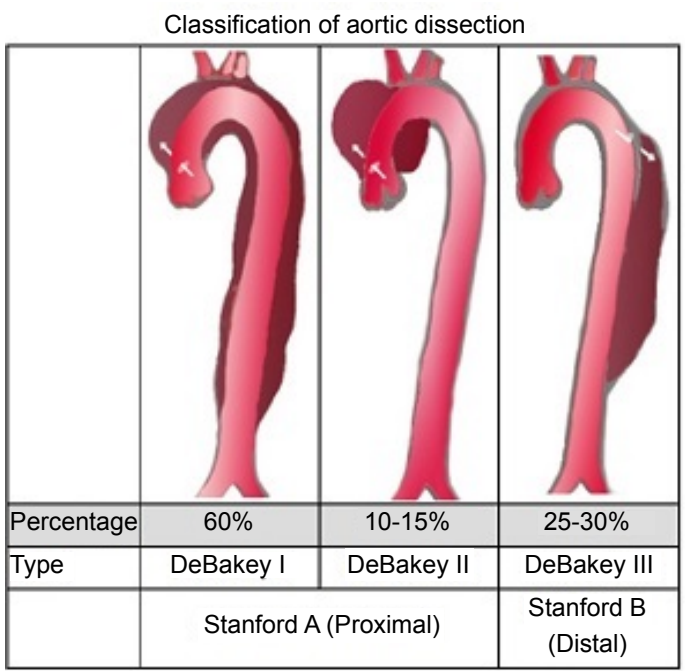

Figure 4: Classification of aortic dissection. aortic dissection, there was little to distinguish between patients with smaller or larger diameters of the ascending aorta, apart from more symptoms of cerebral malperfusion in the patients with smaller aortic diameters, and more congestive heart failure in the patients with larger aortic diameters (both $\mathrm{P}=0.05$ ) [10].

In aortic dissection, early diagnosis is critical because early intervention can decrease the mortality rate, which is estimated to increase by $1 \%$ to $2 \%$ per hour in the first $48 \mathrm{~h}$ of ascending aortic dissection [23].

A recent meta-analysis by Shiga et al. [24] that reviewed published studies of the diagnosis of aortic dissection by TEE, helical CT and MRI showed that these tests have equal and reliable diagnostic value. TEE had $99 \%$ sensitivity and $95 \%$ specificity, helical CT had $100 \%$ sensitivity and $98 \%$ specificity, and MRI had $98 \%$ sensitivity and $98 \%$ specificity [22,25].

Echocardiography provides important information not only regarding the function of the heart, but also the presence of complications of aortic dissection, such as pericardial effusion and Mediastinal hematoma [22]

It is important to differentiate between different classes of aortic dissection because treatment and prognosis vary accordingly. For example, classic type A dissection needs rapid surgical intervention, whereas classic type B dissection needs medical management. It is important to localize the tear, if possible, because the main goal of intervention is to occlude the entry point. Using two-dimensional echocardiography, the intimal flap, point of entry, and true and false lumens can easily be seen [22].

$\mathrm{CT}$ is the most frequent first imaging modality performed, with very high sensitivity and specificity $[10,22]$. MRI has the highest accuracy and sensitivity for detection of all types of dissection, with the exception of class 3, which can only be diagnosed with aortography [22]. Chest $\mathrm{X}$-rays normally show a widened mediastinum. In one study $69 \%$ of patients with aortic dissection were reported to have a widened mediastinum. Significantly more patients with dissections that have diameters of less than $5.5 \mathrm{~cm}$ had a normal chest $\mathrm{x}$-ray $(12.1 \%$ versus $6.8 \%, \mathrm{P}=0.05)$ [10].

Aortic aneurysm is usually a progressive disease that needs to be monitored closely or treated. As aneurysms grow in size, there is an increased incidence of rupture, dissection and death. Ascending aortic aneurysms grow an average of $1 \mathrm{~mm}$ to $4 \mathrm{~mm}$ every year, but in patients with bicuspid aortic valves and Marfan syndrome, the rate of growth is more rapid $[22,26,27]$.

Aortic rupture and older age were risk factors for operative mortality, but the only variable associated with long-term mortality was increasing age. The patients who underwent surgery had an actuarial survival at one, five and 10 years of $92 \%$ (95\% CI 91\% to 93\%), $77 \%$ ( $95 \%$ CI $75 \%$ to $80 \%$ ) and $57 \%$ (95\% CI 53\% to 61\%), respectively [16].

The mainstay of prevention of aortic dissection, aside from treatment of hypertension, is elective aortic surgery in patients with dilated ascending aortas. Guidelines for timing of aortic root repair are based on clinical observations by experienced clinicians and surgeons, and a consensus based on clinical series and patient characteristics. There is a consensus that surgery to prevent rupture or dissection of the ascending TAA should be recommended when the ascending aortic diameter reaches $5.5 \mathrm{~cm}$ for non-Marfan patients and $4.5 \mathrm{~cm}$ in Marfan patients $[10-14,16]$. 
Citation: Barman M, Djamel B, Mathews J (2014) Rare Case of Acute Aortic Dissection in a Young Non-Hypertensive and Non-Pregnant Lady. J Cardiovasc Dis Diagn 2: 154. doi:10.4172/2329-9517.1000154

\section{Conclusion}

Acute aortic dissection is a life-threatening disease with a very high rate of cardiovascular morbidity and mortality. The most important and common risk factor is the systemic hypertension which has been reported in the $70 \%$ of the patients with aortic dissection. Most of the aortic dissection observed in young women has been reported to be related to pregnancy. Pregnancy is considered to be an independent risk factor for aortic dissection however underlying mechanisms are not completely known. Since mortality increases dramatically every hour when the diagnosis and treatment of aortic dissection are not performed, it is very important to make differential diagnosis quickly in such cases. Selection of treatment modality in aortic dissection is based on the type of dissection. In Type A dissection aortic repair is recommended. Type B dissection is usually asymptomatic rather than Type A dissections and probably many patients are overlooked. In Type B dissection, medical treatment is the first choice and involves nitrates and $\beta$-blockers combination.

\section{References}

1. Bonow RO, Mann DL, Zipes DP, Libby P (2012) Braunwald's Heart Disease A Textbook of Cardiovascular Medicine $9^{\text {th }}$ Edn. Elsevier saunders Publisher.

2. Bickerstaff LK, Pairolero PC, Hollier LH, Melton LJ, Van Peenen HJ, et al (1982) Thoracic aortic aneurysms: a population-based study. Surgery 92 1103-1108.

3. Mészáros I, Mórocz J, Szlávi J, Schmidt J, Tornóci L, et al. (2000) Epidemiology and clinicopathology of aortic dissection. Chest 117: 1271-1278.

4. Clouse WD, Hallett JW Jr, Schaff HV, Spittell PC, Rowland CM, et al (2004) Acute aortic dissection: population-based incidence compared with degenerative aortic aneurysm rupture. Mayo ClinProc 79: 176-180.

5. Tsai TT, Evangelista A, Nienaber CA, Trimarchi S, Sechtem U, et al. (2006) Long-term survival in patients presenting with type A acute aortic dissection: insights from the International Registry of Acute Aortic Dissection (IRAD). Circulation 114: $1350-356$

6. vonKodolitsch Y, Schwartz AG, Nienaber CA (2000) Clinical prediction of acute aortic dissection. Arch Intern Med 160: 2977-2982.

7. Mehta RH, O'Gara PT, Bossone E, Nienaber CA, Myrmel T, et al. (2002) Acute type $A$ aortic dissection in the elderly: clinical characteristics, management, and outcomes in the current era. J Am CollCardiol 40: 685-692.

8. Erbel R, Alfonso F, Boileau C, Dirsch O, Eber B, et al. (2001) Diagnosis and management of aortic dissection. Eur Heart J 22: 1642-1681.

9. Cigarroa JE, Isselbacher EM, DeSanctis RW, Eagle KA (1993) Diagnostic imaging in the evaluation of suspected aortic dissection. Old standards and new directions. N Engl J Med 328: 35-43.

10. Erbel R, Engberding R, Daniel W, Roelandt J, Visser C, et al. (1989) Echocardiography in diagnosis of aortic dissection. Lancet 1: 457-461.

11. Bansal RC, Chandrasekaran K, Ayala K, Smith DC (1995) Frequency and explanation of false negative diagnosis of aortic dissection by aortography and transesophageal echocardiography. J Am CollCardiol 25: 1393-1401.
12. White RD, Lipton MJ, Higgins CB, Federle MP, Pogany AC, et al. (1986) Noninvasive evaluation of suspected thoracic aortic disease by contrastenhanced computed tomography. Am J Cardiol 57: 282-290.

13. Nienaber CA, von Kodolitsch Y, Nicolas V, Siglow V, Piepho A, et al. (1993) The diagnosis of thoracic aortic dissection by noninvasive imaging procedures. N Engl J Med 328: 1-9.

14. Vasile N, Mathieu D, Keita K, Lellouche D, Bloch G, et al. (1986) Computed tomography of thoracic aortic dissection: accuracy and pitfalls. J Comput Assist Tomogr 10: 211-215.

15. Sommer T, Fehske W, Holzknecht N, Smekal AV, Keller E, et al. (1996) Aortic dissection: a comparative study of diagnosis with spiral CT, multiplanartransesophageal echocardiography, and MR imaging. Radiology 199: 347-352.

16. Hamada S, Takamiya M, Kimura K, Imakita S, Nakajima N, et al. (1992) Type A aortic dissection: evaluation with ultrafast CT. Radiology 183: 155-158.

17. Sebastià C, Pallisa E, Quiroga S, Alvarez-Castells A, Dominguez R, et al. (1999) Aortic dissection: diagnosis and follow-up with helical CT. Radiographics 19: $45-60$

18. Debakey Me, Henly Ws, Cooley Da, Morris Gc Jr, Crawford Es, et al (1965) Surgical Management Of Dissecting Aneurysms Of The Aorta. J ThoracCardiovascSurg 49: 130-149.

19. Daily PO, Trueblood HW, Stinson EB, Wuerflein RD, Shumway NE (1970) Management of acute aortic dissections. Ann ThoracSurg 10: 237-247.

20. Pansini S, Gagliardotto PV, Pompei E, Parisi F, Bardi G, et al. (1998) Early and late risk factors in surgical treatment of acute type $A$ aortic dissection. Ann ThoracSurg 66: 779-784.

21. Kawahito K, Adachi $H$, Yamaguchi A, Ino $T$ (2001) Preoperative risk factors for hospital mortality in acute type A aortic dissection. Ann ThoracSurg 71: 1239-1243.

22. Nienaber CA, Fattori R, Lund G, Dieckmann C, Wolf W, et al. (1999) Nonsurgical reconstruction of thoracic aortic dissection by stent-graft placement. $\mathrm{N}$ Engl J Med 340: 1539-1545.

23. Liao MF, Jing ZP, Bao JM, Zhao ZQ, Mei ZJ, et al. (2006) Role of nitric oxide and inducible nitric oxide synthase in human abdominal aortic aneurysms: a preliminary study. Chin Med J (Engl) 119: 312-318.

24. Shiga T, Wajma Z, Aptel CC, Inove T, Ohe Y (2006) Diagnostic accuracy of transesophageal echocardiography, helical computed tomography, and magnetic resonance imaging for suspected thoracic aortic dissection. Symptomatic review and meta-analysis. Arch Intern Med 166: 1350-1356.

25. Fleming C, Whitlock EP, Beil TL, Lederle FA (2005) Screening for abdominal aortic aneurysm: a best-evidence systematic review for the U.S. Preventive Services Task Force. Ann Intern Med 142: 203-211.

26. Tsai TT, Nienaber CA, Eagle KA (2005) Acute aortic syndromes. Circulation 112: $3802-3813$

27. Erbel R, Alfonso F, Boileau C, Dirsch O, Eber B, et al. (2001) Diagnosis and management of aortic dissection. Eur Heart J 22: 1642-1681. 